\title{
Melt processability, characterization, and antibacterial activity of compression-molded green composite sheets made of poly(3- hydroxybutyrate-co-3-hydroxyvalerate) reinforced with coconut fibers impregnated with oregano essential oil
}

\author{
S. Torres-Giner ${ }^{\mathrm{a}, *}$, L. Hilliou ${ }^{\mathrm{b}}$, B. Melendez-Rodriguez ${ }^{\mathrm{a}}$, K.J. Figueroa-Lopez ${ }^{\mathrm{a}}$, D. Madalena ${ }^{\mathrm{c}}$, \\ L. Cabedo ${ }^{\mathrm{d}}$, J.A. Covas ${ }^{\mathrm{b}}$, A.A. Vicente ${ }^{\mathrm{c}}$, J.M. Lagaron $^{\mathrm{a}}$

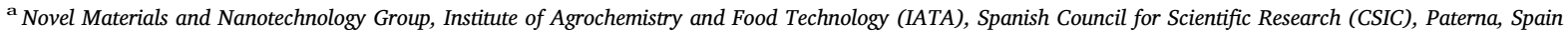 \\ ${ }^{\mathbf{b}}$ Institute for Polymers and Composites/I3N, University of Minho, Guimarães, Portugal \\ ${ }^{c}$ CEB - Centre of Biological Engineering, University of Minho, Braga, Portugal \\ d Polymers and Advanced Materials Group (PIMA), Universitat Jaume I (UJI), Castellón, Spain
}

\section{A R T I C L E I N F O}

\section{Keywords:}

PHBV

Coir

Essential oils

Active packaging

Agro-food waste valorization

\begin{abstract}
A B S T R A C T
New packaging materials based on green composite sheets consisting of poly(3-hydroxybutyrate-co-3-hydroxyvalerate) (PHBV) and coconut fibers (CFs) were obtained by twin-screw extrusion (TSE) followed by compression molding. The effect of varying the $\mathrm{CF}$ weight content, i.e. $1,3,5$, and $10 \mathrm{wt} . \mathrm{-} \%$, and the screw speed during melt processing, i.e. 75, 150, and $225 \mathrm{rpm}$, on both the aspect ratio and dispersion of the fibers was analyzed and related to the properties of the compression-molded sheets. Finally, the CFs were impregnated with oregano essential oil (OEO) by an innovative spray coating methodology and then incorporated into PHBV at the optimal processing conditions. The functionalized green composite sheets presented bacteriostatic effect against Staphylococcus aureus from fiber contents as low as $3 \mathrm{wt} .-\%$. Therefore, the here-prepared CFs can be successfully applied as natural vehicles to entrap extracts and develop green composites of high interest in active food packaging to provide protection and shelf life extension.
\end{abstract}

\section{Introduction}

The use of agro-food residues for the preparation of polymer composites is gaining a significant attention due to their huge availability and low price, being at the same time a highly sustainable strategy for waste valorization. Natural fibers (NFs), particularly those obtained from plants, represent an environmentally friendly and unique choice to reinforce bioplastic matrices due to their relative high strength and stiffness (Yang, Kim, Park, Lee, \& Hwang, 2006). The substitution of oilderived polymers with bio-based polymers as the matrix component results in the term "green composites" (Zini \& Scandola, 2011), which indicates that the composite as a whole, i.e. both matrix and reinforcement, originates from renewable resources. In this regard, the incorporation of NFs such as jute, sisal, flax, hemp, and bamboo fibers into biopolymers has been recently intensified (Bogoeva-Gaceva et al., 2007). Resultant green composites do not only offer environmental advantages over traditional polymer composites, such as reduced dependence on non-renewable energy/material sources, lower greenhouse gas and pollutant emissions, improved energy recovery, and end-of-life biodegradability of components (Joshi, Drzal, Mohanty, \& Arora, 2004), but also a potential reduction of both product density and energy requirements for processing (Faruk, Bledzki, Fink, \& Sain, 2014).

Polyhydroxyalkanoates (PHAs) comprise a family of biodegradable aliphatic polyesters produced by microorganisms. PHAs show the highest potential to replace polyolefins in a wide range of applications, including packaging, due to their high mechanical strength and water resistance (Bugnicourt, Cinelli, Lazzeri, \& Alvarez, 2014). Among PHAs, poly(3-hydroxybutyrate) (PHB) and its copolymer with 3-hydroxyvalerate (HV), i.e. poly(3-hydroxybutyrate-co-3-hydroxyvalerate) (PHBV), have so far received the greatest attention in terms of pathway characterization and industrial-scale production. The use of PHA copolymers presents certain advantages since they have a lower melting point and higher flexibility than their homopolymers, which improves melt stability and broadens their processing window (Torres-Giner, Montanes, Boronat, Quiles-Carrillo, \& Balart, 2016). Furthermore, the

\footnotetext{
* Corresponding author

E-mail address: storresginer@iata.csic.es (S. Torres-Giner).
} 
introduction of comonomer units induces defects in the crystal lattice, reducing both the degree of crystallinity and crystallization rate (Kunioka, Tamaki, \& Doi, 1989).

Several plant-derived NFs, such as regenerated and/or recycled cellulose, pineapple leaf fibers (PALF), wheat straw fibers, wood floor, jute fibers, flax fibers, banana, sisal, and coir fibers, hemp fibers, abaca fibers, bamboo fibers, sugarcane bagasse fibers, kenaf and lyocell fibers, wood powder, and pita (agave) fibers, have been so far studied as sustainable reinforcements to produce PHA-based composite materials (Torres-Giner, Montanes, Fombuena, Boronat, \& Sanchez-Nacher, 2016). Recently, cellulose fibers from wheat straw and other by-products have been used in the European Projects ECOBIOCAP and YPACK as a cheap source of fillers to reduce the cost of a PHA matrix for packaging applications, where up to $20 \%$ of cellulose fibers were allowed in the final composition. Some previous research studies have also suggested that the incorporation of NFs can definitely strengthen the mechanical performance of both PHB and PHBV and, in some cases, also improve biodegradability (Avella et al., 2000; Barkoula, Garkhail, \& Peijs, 2010; Teramoto, Urata, Ozawa, \& Shibata, 2004). However, the narrow processing window and the poor melt strength of PHAs are certainly responsible for the rather small number of studies involving extruded composites with potential for being converted into packaging articles such as films and sheets (Cunha et al., 2015). The most promising PHA-based composite manufacturing techniques are extrusion and compression molding, particularly the latter, given the relatively low shear-rates and thermomechanical stresses involved.

Coconut shells represent a good example of agro-industrial non-food feedstock that is still considered as waste, for which relevant industrial new end uses are being currently pursued (Rosa et al., 2009). In particular, it is estimated that around 55 billion coconuts are produced annually worldwide. Most of their husks are abandoned, creating a waste of natural resources and a cause of environmental pollution ( $\mathrm{Gu}$, 2009). The coconut fibers (CFs), also referred as coir when completely ground up, are plant-derived NFs of the coconut fruit obtained from the palm tree (Cocos nucifera L.). The CFs are present in the mesocarp, which constitutes 30-35 wt.-\% of the coconut (Tomczak, Sydenstricker, \& Satyanarayana, 2007). Individual CFs show a length of $0.3-1.0 \mathrm{~mm}$ and a diameter of $0.01-0.02 \mathrm{~mm}$, resulting in an average aspect ratio of approximately 35 (Hasan, Hoque, Mir, Saba, \& Sapuan, 2015). The CFs are also characterized by a high toughness and durability as well as improved thermal stability due to their high lignin content ( $\sim 40 \%)$ and relatively low cellulose content $(\sim 32 \%)$ (Rosa et al., 2010$)$. These lignocellulosic fibers are not only abundant in tropical countries but also versatile, renewable, cheap, and biodegradable. Therefore, they could become potential substitutes for energy-intensive synthetic fibers in many applications where high strength and modulus are not required (Satyanarayana et al., 1982).

The CFs have been tested as reinforcing fillers upon the formulation of different thermoplastic materials, such as low-density polyethylene (LDPE) (Choudhury, Kumar, \& Adhikari, 2007; Owolabi \& Czvikovszky, 1988) and linear low-density polyethylene (LLDPE) (Choudhury et al., 2007), polypropylene (PP) (Gu, 2009; Hasan et al., 2015; Mir, Nafsin, Hasan, Hasan, \& Hassan, 2013; Owolabi \& Czvikovszky, 1988; Wambua, Ivens, \& Verpoest, 2003), poly(vinyl chloride) (PVC) (Owolabi \& Czvikovszky, 1988), starch-gluten (Corradini, Rosa, Mazzetto, Mattoso, \& Agnelli, 2006), natural rubber (NR) (Geethamma, Thomas Mathew, Lakshminarayanan, \& Thomas, 1998), among others. These previous studies have demonstrated that the incorporation of both untreated and chemically modified CFs into polymer formulations can represent a feasible route to produce low-cost composites with a moderate improvement of the mechanical properties. Interestingly, the CFs are exceptionally hydrophilic as they contain strongly polarized hydroxyl groups on their surface (Westerlind \& Berg, 1988). CFs are thus inherently capable to adsorb and hold moisture up to 7-9 times their weight, being proposed as biosorbents for water treatment (Bhatnagar, Vilar, Botelho, \& Boaventura, 2010). The outstanding capacity of the CFs to retain water and other polar components certainly opens up new attractive opportunities for potential uses as vehicle of functional and bioactive substances.

The particular chemical and morphological characteristics of the CFs can be explored to adsorb essential oils (EOs), i.e. aromatic and volatile oily liquids obtained from herbs and spices. Most EOs and their constituents are categorized as Generally Recognized as Safe (GRAS) by the U.S. Food and Drug Administration (López, Sánchez, Batlle, \& Nerín, 2007). Among EOs, oregano essential oil (OEO), extracted from Origanum vulgare L., is well-recognized for its antioxidative and antimicrobial action in the food industry (Hosseini, Zandi, Rezaei, \& Farahmandghavi, 2013). The biocide performance of OEO has been mainly attributed to its rich composition in phenolic compounds, namely carvacrol (up to $80 \%$ ), thymol (up to 64\%), and the monoterpene hydrocarbons $\gamma$-terpinene and p-cymene (both up to 52\%) (Burt, 2004). The incorporation of OEO in plastic films to avoid microbial food spoilage currently represents an attractive option for packaging manufacturers. Several studies have demonstrated its efficacy in inhibiting microbial development and synthesis of microbial metabolites, including pathogenic bacteria, yeasts, and molds (Benavides et al., 2012; Hosseini, Rezaei, Zandi, \& Farahmandghavi, 2015; Oussalah, Caillet, Salmiéri, Saucier, \& Lacroix, 2004; Pelissari, Grossmann, Yamashita, \& Pineda, 2009; Seydim \& Sarikus, 2006; Zivanovic, Chi, \& Draughon, 2005). Besides imparting antimicrobial characteristics to the films, OEO can change flavor, aroma, and odor. Nevertheless, similarly as with other EOs, OEO is volatile and easily evaporates and/or decomposes during processing and preparation of the antimicrobial films. Therefore, its direct exposure to heat, pressure, light or oxygen is a technological challenge.

The objective of the present study was to originally explore the inherent capacity of the CFs to adsorb and hold polar components in order to develop, by conventional melt-processing methodologies, PHBV-based green composite sheets with antimicrobial properties of interest in active packaging applications. To this end, the first part of the study was focused on optimizing the processing conditions of the green composites. In particular, it was analyzed the effect of varying both the CF weight content and the screw speed during melt processing on the aspect ratio and dispersion of the fibers in the PHBV matrices. In the second part, for the optimal processing conditions, the thermal, mechanical, and barrier properties of the compression-molded PHBV sheets were evaluated as a function of the $\mathrm{CF}$ content. In the last part, the CFs were impregnated with OEO by an innovative spray coating methodology, incorporated again into PHBV, and the antimicrobial properties of the green composite sheets were evaluated.

\section{Experimental}

\subsection{Materials}

Bacterial aliphatic copolyester PHBV was ENMAT ${ }^{\text {Tm }}$ Y1000 P, produced by Tianan Biologic Materials (Ningbo, China) and distributed by NaturePlast (Ifs, France). The product was delivered as off-white pellets packaged in plastics bags. The biopolymer resin presents a true density of $1.23 \mathrm{~g} / \mathrm{cm}^{3}$ and a bulk density of $0.74 \mathrm{~g} / \mathrm{cm}^{3}$, as determined by ISO 1183 and ISO 60, respectively. The melt flow index (MFI) is 5-10 g/ $10 \mathrm{~min}\left(190^{\circ} \mathrm{C}, 2.16 \mathrm{~kg}\right)$, as determined by ISO 1133 . The molar fraction of $\mathrm{HV}$ in the copolymer is $2-3 \%$, whereas the weight-average molecular weight $\left(\mathrm{M}_{\mathrm{W}}\right)$ is approximately $2.8 \times 10^{5} \mathrm{~g} / \mathrm{mol}$. According to the manufacturer, this resin is suitable for injection molding, thermoforming, and extrusion.

CFs were kindly supplied by Amorim Isolamentos, S.A. (Mozelos, Portugal) in the form of a liner roll. The fibrous layers were obtained from ripe coconuts, which were manually de-husked from the hard shell by driving the fruit down onto a spike to split it. $100 \%$ pure OEO was purchased from Gran Velada S.L. (Zaragoza, Spain) while food-grade paraffinic oil (grade 9578) was obtained from Quimidroga S.A. 

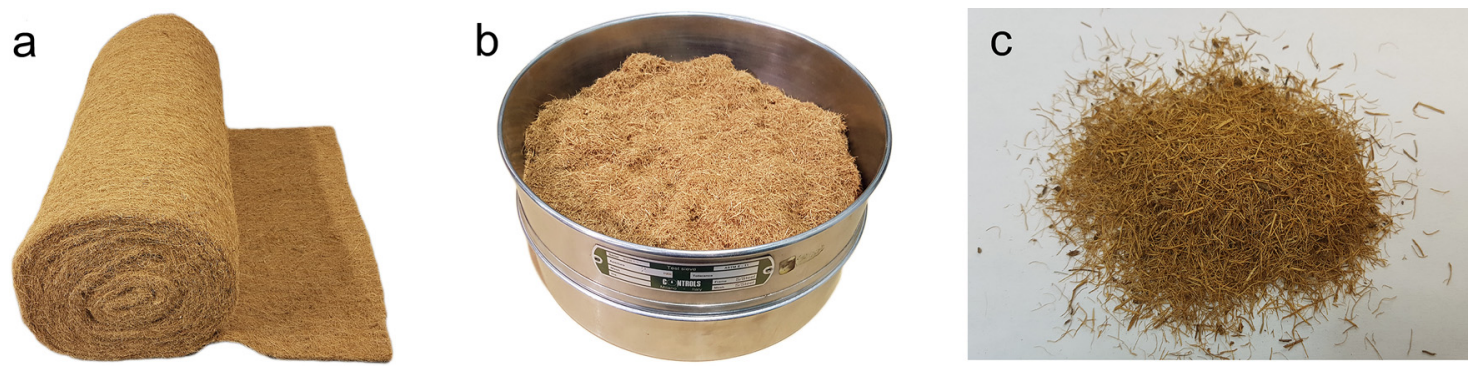

Fig. 1. (a) As-received reel of coconut fibers (CFs); (b) Ground CFs; (c) Sieved CFs.

(Barcelona, Spain). 2,2,2-trifuoroethanol (TFE) with 99\% purity, D-limonene with $98 \%$ purity, Nile Red (9-diethylamino-5H-benzo- $\alpha$-phenoxazine-5-one), and dimethyl sulfoxide (DMSO) anhydrous with purity $\geq 99.9 \%$ were all purchased from Sigma-Aldrich S.A. (Madrid, Spain). All chemical reagents were utilized as received.

\subsection{Fibers functionalization}

CFs were initially separated from the roll and chopped to a length of ca. $5 \mathrm{~mm}$ in a Granulator 20-18/JM from Grindo S.R.L. (Cologno Monzese, Italy). Chopped fibers were then sieved using a Test sieve model from Controls S.p.A. (Milano, Italy) with an aperture of $2 \mathrm{~mm}$. The resultant bulk density of the CFs was $0.14 \mathrm{~g} / \mathrm{cm}^{3}$, as determined by ISO 60. Fig. 1 shows the different stages followed for the preparation of the CFs.

Part of the obtained CFs was impregnated with OEO in order to provide them with antibacterial functionality, the here so-called functionalization. For this purpose, a 2:1 (vol./vol.) paraffinic oil/OEO solution was prepared, as this was the highest OEO content without creating phase separation. This solution, with a density of $0.902 \mathrm{~g} / \mathrm{mL}$, was added at $15 \mathrm{wt} .-\%$ to the CFs by means of an air spray gun from Nutool (Doncaster, UK) connected to a 241 1.0HP PWB24S air compressor from PowerED ${ }^{\circledR}$ (Amiais de Baixo, Portugal) working at 2 bar. This way, the dried CFs were sprayed every $5 \mathrm{~s}$ while rotating at $58 \mathrm{rpm}$ inside a drum attached to an ARTISAN 5KSM125EER household mixer from KitchenAid ${ }^{\circledR}$ (Michigan, USA).

\subsection{Preparation of green composites}

Prior to melt processing, the PHBV pellets and CFs were dried for $4 \mathrm{~h}$ at $80^{\circ} \mathrm{C}$ in an oven to remove the residual humidity. Then, different PHBV formulations were melt compounded by twin-screw extrusion (TSE) varying the CF content, i.e. $0,1,3,5$, and $10 \mathrm{wt} .-\%$, in a corotating intermeshing twin-screw extruder LSM $34 \mathrm{Gl}$ from Leistritz AG (Nuremberg, Germany). The screws have a diameter (D) of $34 \mathrm{~mm}$ and a length-to-diameter ratio (L/D) of 29. The modular barrel is equipped with 8 individual heating zones and is coupled to a strand die. The extruder layout with the detailed screw configuration is presented in Fig. 2. Basically, the screw contains two mixing zones, each consisting of a series of kneading disks staggered at $90^{\circ}$ (in order to induce dispersion), that are separated by conveying sections that work mostly partially filled. The components are fed separately upstream of each

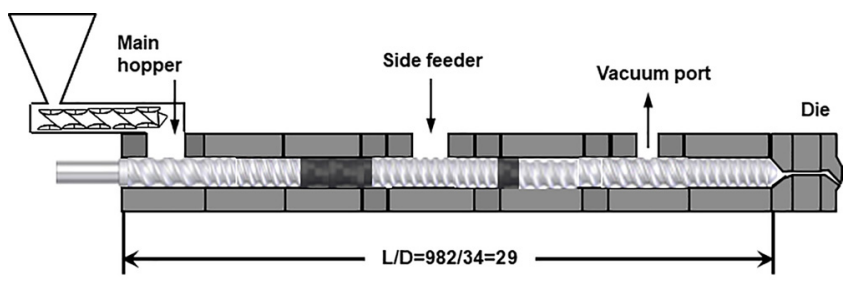

60R/60R4/45R2/30R2/8KB90\%/20R2/45R/30R/4kB90\%/30R/30R2/30R2/20R4/20R2

Fig. 2. Detailed cylinder with screw configuration. mixing zone. The PHBV pellets were fed into the main hopper with a volumetric DVM18-L feeder from Moretto S.p.A. (Massanzago, Italy) at a feeding rate of $2 \mathrm{~kg} / \mathrm{h}$. The CFs were first pre-mixed in a zipped bag with 1 part per hundred resin (phr) of paraffinic oil and then introduced in the extruder after melting the polymer, at $\mathrm{L} / \mathrm{D}=12$, through the side feeder. As commonly faced with other low-density fibers, there were difficulties in guaranteeing a precise and constant feeding throughput. A venting port at $\mathrm{L} / \mathrm{D}=23$ coupled to a vacuum pump enabled the removal of both residual moisture and volatiles. Three different screw speeds were tested, i.e. 75,150 , and $225 \mathrm{rpm}$, and the following decreasing temperature profile was fixed (from hopper to die): $195 / 190 /$ $185 / 180 / 175 / 170 / 165 / 160^{\circ} \mathrm{C}$. The extruded strand was cooled in a water bath, dried with an air-knife, and then pelletized by a rotary cutter. The minimum residence time was estimated by measuring the time that a blue masterbatch pellet would take from being introduced directly into the extruder until exiting from the die.

The compounded pellets were shaped into sheets with a thickness of $\sim 500 \mu \mathrm{m}$ by compression molding using a hydraulic press from Geo E. Moore \& Son (Bham.) Ltd. (Birmingham, UK). About $10 \mathrm{~g}$ of material were placed in a hollow aluminum mold of $10 \times 10 \mathrm{~cm}^{2}$ and then introduced into the press. Materials were initially preheated at $190^{\circ} \mathrm{C}$ for $1 \mathrm{~min}$, without pressure, and subsequently hot-pressed for $3 \mathrm{~min}$ at 4 tons. Finally, the samples were cooled down to $25^{\circ} \mathrm{C}$ by means of an internal water circulating system.

\subsection{Characterization methods}

\subsubsection{Sheet thickness and samples conditioning}

The thickness of the compression-molded sheets was measured with a digital micrometer series 500014 from Mitutoyo Corporation (Kawasaki, Japan), having $\pm 0.001 \mathrm{~mm}$ accuracy, at five random positions. Samples were aged for at least 15 days prior to any physical characterization in a desiccator at $25{ }^{\circ} \mathrm{C}$ and $0 \%$ relative humidity (RH).

\subsubsection{Optical microscopy}

Dispersion quality of CFs in the green composites was assessed with a light transmission optical microscope Olympus BH-2 from Olympus Optical Co., Ltd (Tokyo, Japan), coupled to a digital camera system Leica DFC280 from Meyer Instruments, Inc. (Houston, Texas, USA). Fiber attrition was investigated by monitoring fiber length distribution on the PHBV composites processed with different CF contents and at different conditions. This method was performed by immersing a small sample of each specimen in TFE solvent at room temperature for $12 \mathrm{~h}$. The resultant solution was centrifuged and filtered so that PHBV was removed and the recovered CFs were deposited onto microscopy glass slabs for observation.

The OEO-containing CFs were analyzed by fluorescence microscopy using an Olympus BX51 from Olympus Optical Co., Ltd. The samples were previously dyed with Nile Red, a lipophilic dye, in a $0.25 \mathrm{mg} / \mathrm{ml}$ solution of DMSO at 1:10 dye/sample (vol./vol.), covered in aluminum foil to protect them from light exposure, and dried at $25^{\circ} \mathrm{C}$ for at least $12 \mathrm{~h}$ prior to observation. The samples were analyzed at an emission wavelength between 470 and $490 \mathrm{~nm}$. 


\subsubsection{Melt flow index}

MFI of the neat PHBV and its green composites pellets were measured at $185^{\circ} \mathrm{C}$ with a load of $1.2 \mathrm{~kg}$ using a MFI Daventest LPF-002 from Lloyd Instruments Ltd. (Bognor Regis, UK). Higher temperatures and weights triggered excessive mass outputs that impaired measurement accuracy. Data were reported as the mean value and standard error computed from 10 tests.

\subsubsection{Thermal analysis}

Thermal transitions were analyzed by differential scanning calorimetry (DSC) on a DSC-7 analyzer from PerkinElmer, Inc. (Waltham, MA, USA), equipped with a cooling accessory Intracooler 2 also from PerkinElmer, Inc. A heating step from -30 to $200{ }^{\circ} \mathrm{C}$ was followed by a cooling step to $-30{ }^{\circ} \mathrm{C}$ under nitrogen atmosphere with a flow-rate of $20 \mathrm{~mL} / \mathrm{min}$. The scanning rate was $10^{\circ} \mathrm{C} / \mathrm{min}$ and an empty aluminum pan was used as reference. Calibration was performed using an indium sample. All tests were carried out at least in triplicate. The glass transition temperature $\left(\mathrm{T}_{\mathrm{g}}\right)$, cold crystallization temperature $\left(\mathrm{T}_{\mathrm{cc}}\right)$, enthalpy of cold crystallization $\left(\Delta \mathrm{H}_{\mathrm{cc}}\right)$, melting temperature $\left(\mathrm{T}_{\mathrm{m}}\right)$, and enthalpy of melting $\left(\Delta \mathrm{H}_{\mathrm{m}}\right)$ were obtained from the first heating scan, while the crystallization temperature from the melt $\left(\mathrm{T}_{\mathrm{c}}\right)$ and enthalpy of crystallization $\left(\Delta \mathrm{H}_{\mathrm{c}}\right)$ were determined from the cooling scan. The percentage of crystallinity $\left(X_{c}\right)$ was determined using the following expression:

$\mathrm{Xc}=\left[\frac{\Delta \mathrm{Hm}-\Delta \mathrm{Hcc}}{\Delta \mathrm{H}_{\mathrm{m}}^{0} \cdot(1-\mathrm{w})}\right] \cdot 100$

where $\Delta \mathrm{H}_{\mathrm{m}}{ }^{\circ}=146.6 \mathrm{~J} / \mathrm{g}$ is the enthalpy corresponding to the melting of a $100 \%$ crystalline PHB sample (Barham, Keller, Otun, \& Holmes, 1984) while the term 1- $w$ represents the biopolymer weight fraction in the composite.

Thermogravimetric analysis (TGA) was performed in a TG-STDA model TGA/STDA851e/LF/1600 thermobalance from Mettler-Toledo, LLC (Columbus, OH, USA). The samples, with a weight of $\sim 15 \mathrm{mg}$, were heated from 50 to $900{ }^{\circ} \mathrm{C}$ at a heating rate of $10^{\circ} \mathrm{C} / \mathrm{min}$ under a nitrogen flow-rate of $50 \mathrm{~mL} / \mathrm{min}$.

\subsubsection{Tensile tests}

Dumbbell $500 \mu \mathrm{m}$-thick samples were die-cut from the compressionmolded sheets and conditioned to ambient conditions, i.e. $25{ }^{\circ} \mathrm{C}$ and $50 \% \mathrm{RH}$, for $24 \mathrm{~h}$. Tensile tests were carried out at room temperature in a universal mechanical testing machine AGS-X $500 \mathrm{~N}$ from Shimadzu Corp. (Kyoto, Japan) in accordance with ASTM D638 (Type IV) standard. This was equipped with a $1-\mathrm{kN}$ load cell and the cross-head speed was $10 \mathrm{~mm} / \mathrm{min}$. A minimum of six specimens were measured for each sample.

\subsubsection{Permeability tests}

The water vapor permeability (WVP) and limonene permeability (LP) were determined according to the ASTM 2011 gravimetric method. In the case of WVP, $5 \mathrm{ml}$ of distilled water were poured into a Payne permeability cup $(\varnothing=3.5 \mathrm{~cm}$ ) from Elcometer Sprl (Hermalle-sousArgenteau, Belgium). The sheets were placed in the cups so that on one side they were exposed to $100 \% \mathrm{RH}$, avoiding direct contact with water. The cups containing the sheets were then secured with silicon rings and stored in a desiccator at $25^{\circ} \mathrm{C}$ and $0 \% \mathrm{RH}$. Identical cups with aluminum foils were used as control samples to estimate water loss through the sealing. The cups were weighed periodically using an analytical balance with $\pm 0.0001 \mathrm{~g}$ accuracy. Water vapor permeation rate (WVPR), also called water permeance when corrected for permeant partial pressure, was determined from the steady-state permeation slope obtained from the regression analysis of weight loss data per unit area versus time, in which the weight loss was calculated as the total cell loss minus the loss through the sealing. WVP was obtained, in triplicate, by correcting the permeance by the average sheet thicknesses.

For LP, similarly, $5 \mathrm{ml}$ of D-limonene was placed inside the Payne permeability cups and the cups containing the sheets were stored under controlled conditions, i.e. $25{ }^{\circ} \mathrm{C}$ and $40 \%$ RH. Limonene permeation rate (LPR) was obtained from the steady-state permeation slopes and the weight loss was calculated as the total cell loss minus the loss through the sealing plus the water sorption gained from the environment measured in samples with no permeant. LP was calculated taking into account the average sheet thickness in each case, measuring three replicates per sample.

Oxygen permeability (OP) was obtained from the oxygen transmission rate (OTR) measurements, recorded in duplicate, using an Oxygen Permeation Analyzer M8001 from Systech Illinois (Thame, UK) at $25{ }^{\circ} \mathrm{C}$ and $60 \% \mathrm{RH}$. The samples were previously purged with nitrogen in the humidity equilibrated samples and then exposed to an oxygen flow of $10 \mathrm{~mL} / \mathrm{min}$. The exposure area during the test was $5 \mathrm{~cm}^{2}$. Sheet thickness and gas partial pressure were determined. Measurements were performed in duplicate.

\subsubsection{Antibacterial assays}

The antibacterial activity of the neat OEO, the OEO-containing CFs, and the green composite sheets with the OEO-containing CFs was evaluated against Staphylococcus aureus (S. aureus) ATCC 6538 P. This bacterial strain was obtained from the Spanish Type Culture Collection (CECT) (Valencia, Spain) and it was cultivated at optimal growth conditions in tryptone soy broth (TSB) from Oxoid Thermo Scientific (Basingstoke, UK), having a concentration of $6.3 \times 10^{8}$ colony forming units (CFU)/ml. Previous to each study, a $100-\mu \mathrm{l}$ aliquot from the culture was transferred to TSB and grown at $37^{\circ} \mathrm{C}$ to the mid-exponential phase of growth with an approximate count of $5 \times 10^{5} \mathrm{CFU} / \mathrm{ml}$. To ensure sterilization, all materials were initially exposed to ultraviolet (UV) radiation for $30 \mathrm{~min}$ in a Biostar cabinet from Telstar S.A. (Madrid, Spain).

The effectiveness of the OEO and OEO-containing CFs against $S$. aureus was tested following the plate micro-dilution protocol, as described in the Methods for Dilution Antimicrobial. Susceptibility Tests for Bacteria That Grow Aerobically; Approved Standard-Tenth. Edition (M07-A10) by the Clinical and Laboratory Standards Institute (CLSI). For this, a 96-well plate with an alpha numeric coordination system (columns 1-12 and rows A-H) were used, where $10 \mu \mathrm{l}$ of the tested samples were introduced in the wells with $90 \mu$ of the bacteria medium. In the wells corresponding to A, B, C, E, F, and G columns different concentrations of $\mathrm{OEO}$, i.e. $0.078,0.156,0.312,0.625,1.25$, $2.5,5,10,20$, and $40 \mu \mathrm{l} / \mathrm{ml}$, and of OEO-containing CFs, i.e. 0.315 , $0.625,1.25,2.5,5,10,25,50,100$, and $250 \mu \mathrm{g} / \mathrm{ml}$ were tested, in triplicate, from rows 1 to 10 . Columns $\mathrm{D}$ and $\mathrm{H}$ were used as the control of OEO and OEO-containing CFs, respectively, without bacteria. Row 11 was taken as the positive control, i.e. only TSB, and row 12 was used as the negative control, i.e. S. aureus in TSB. The plates were incubated at $37^{\circ} \mathrm{C}$ for $24 \mathrm{~h}$. Thereafter, $10 \mu \mathrm{l}$ of resazurin solution, $100 \mu \mathrm{g} / \mathrm{ml}$ in TBS, a metabolic indicator obtained from MP Biomedicals, LLC (Illkirch, France), was added to each well and incubated again at $37^{\circ} \mathrm{C}$ for $2 \mathrm{~h}$. Upon obtaining the resazurin change, the wells were read through color difference. The minimum inhibitory concentration (MIC) was determined as the lowest concentration of OEO and OEO-containing CFs presenting growth inhibition.

A modification of the Japanese Industrial Standard (JIS) Z 2801:2010 was performed to evaluate the bacterial efficiency on the sheets surface. This technique is useful to determine the antimicrobial activity of finished products, particularly including polymer composite pieces (Torres-Giner, Torres, Ferrándiz, Fombuena, \& Balart, 2017). Briefly, a bacterial suspension of $S$. aureus of about $5 \times 10^{5} \mathrm{CFU} / \mathrm{mL}$ was spread uniformly on the surface of sheets with dimensions of $2 \times 2 \mathrm{~cm}^{2}$ and then covered by an inert 10- $\mu \mathrm{m}$ LDPE film of $1.5 \times 1.5 \mathrm{~cm}^{2}$. After $24 \mathrm{~h}$ of incubation at $95 \% \mathrm{RH}$, bacteria were recovered with phosphate-buffered saline (PBS), inoculated onto tryptic soy agar (TSA) plates, and incubated at $37^{\circ} \mathrm{C}$ for $24 \mathrm{~h}$ to quantify the number of viable bacteria. PHBV sheets with different $\mathrm{CF}$ contents were 
$75 \mathrm{rpm}$
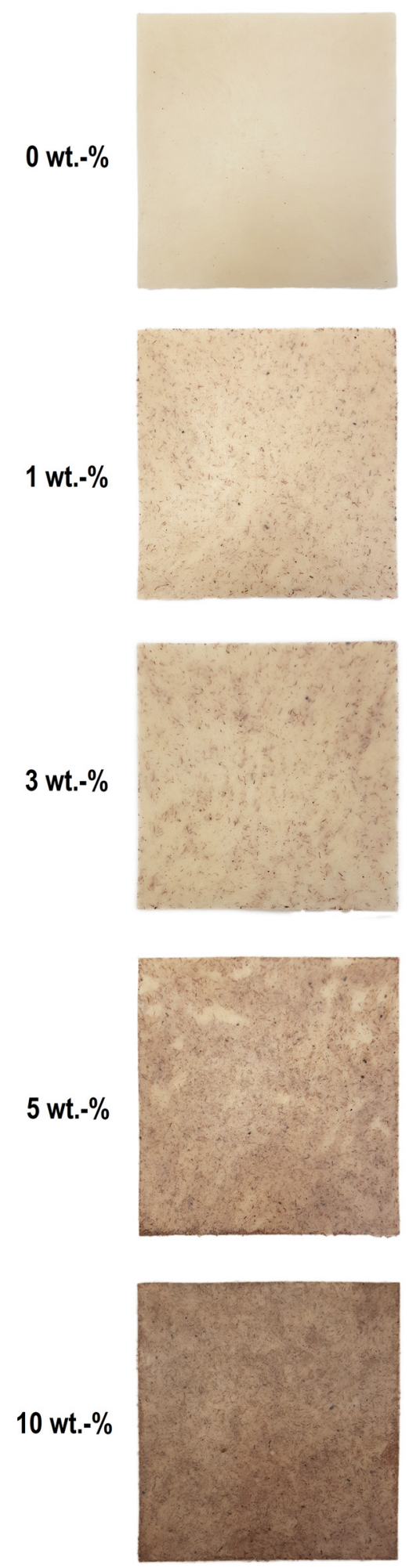

$150 \mathrm{rpm}$
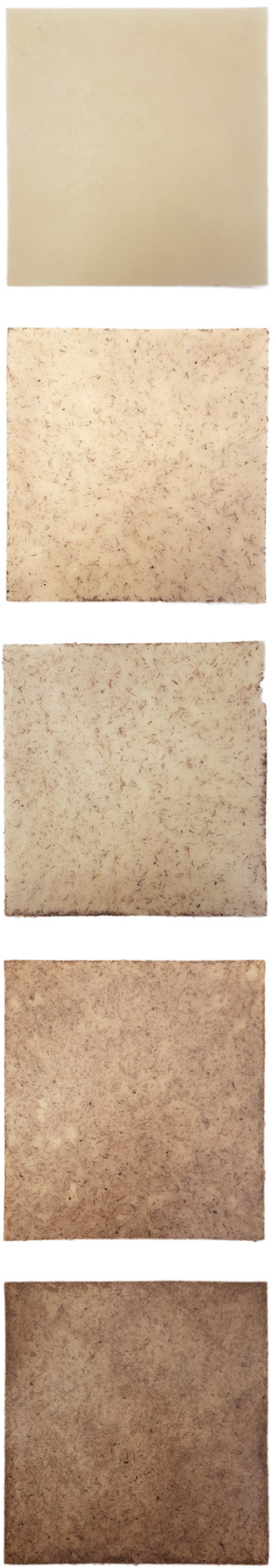

$225 \mathrm{rpm}$
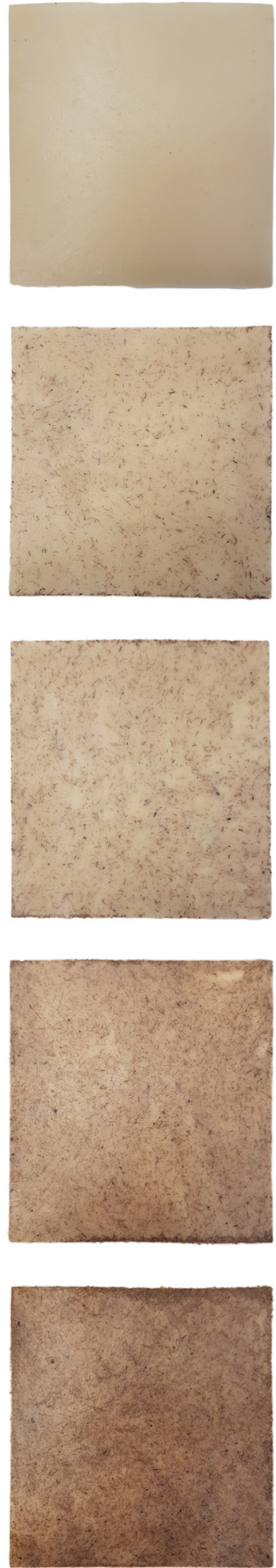

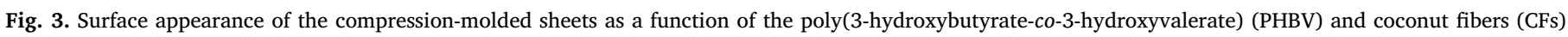
weight content and screw speed.

analyzed, using both sheets without fibers and with fibers without OEO as the negative controls. The antimicrobial activity was evaluated as synthesized, i.e. 1 day after preparation, and 15 days later. Surface reduction $(R)$ was calculated as follows:

$$
R=\left[\log \left(\frac{B}{A}\right)-\log \left(\frac{C}{A}\right)\right]=\log \left(\frac{B}{C}\right)
$$

where $\mathrm{A}$ is the average of the number of viable bacteria on the control sample immediately after inoculation, B is the average of the number of 
viable bacteria on the control sample after $24 \mathrm{~h}$, and $\mathrm{C}$ is the average of the number of viable bacteria on the test sample after $24 \mathrm{~h}$. Three replicate experiments were performed for each sample and the antibacterial activity was evaluated with the following assessment: Nonsignificant $(R<0.5)$, slight $(R \geq 0.5$ and $<1)$, significant $(R \geq 1$ and $<3)$, and strong $(R \geq 3)$.

\section{Results and discussion}

\subsection{Melt processability}

Fig. 3 shows the surface view of the green composite sheets varying the $\mathrm{CF}$ contents and processed at different processing conditions. In all cases, the green composite sheets exhibited a smooth, defect-free, and uniform surface, in which CFs appeared randomly dispersed. Distribution was relatively uniform, albeit some small areas seem to contain lower $\mathrm{CF}$ concentration. As expected, the CF content highly influenced on the color intensity of the PHBV sheets. Then, sheets produced with the highest $\mathrm{CF}$ contents, i.e. 5 and $10 \mathrm{wt} .-\%$, presented a wood-like visual feature, which could be aesthetically suitable to imitate solid wood parts for boards, lids or containers of interest in, for instance, rigid packaging. In contrast, the processing conditions had a minor influence on both surface aspect and distribution of the CFs into the PHBV matrix. Only the sheets obtained from green composites compounded at $225 \mathrm{rpm}$ presented a slight color increase, which was probably caused by thermal degradation arising from the viscous dissipation associated to flow under higher shear-rates.

CFs in the green composite sheets were imaged by optical microscopy, after dissolving and filtrating PHBV. Representative pictures are displayed in Fig. 4. Residence time and fiber dimensions were evaluated in order to select the optimal screw speed for which the set temperature and feed-rate were kept constant. Table 1 reports both characteristics for each composition and screw speed. As expected, at a given feed-rate, residence time was gradually reduced with increasing screw speed, as flow along the screw was more effective and the number of fully filled channels decreased. For instance, for the neat PHBV formulation, residence time decreased from $131 \mathrm{~s}$, at $75 \mathrm{rpm}$, to $97 \mathrm{~s}$ and $64 \mathrm{~s}$, at $150 \mathrm{rpm}$ and $225 \mathrm{rpm}$, respectively. The incorporation of CFs slightly increased the residence time due to their lower bulk density in relation to the PHBV pellets, i.e. the total volume occupied by the material in the extruder increased though the output remained constant. For all processing conditions, CFs presented a similar diameter, varying in the range $100-400 \mu \mathrm{m}$ and with a mean value of approximately $215 \mu \mathrm{m}$, whereas their length significantly decreased with increasing both the content and screw speed. Specifically, the average fiber length decreased from above $1900 \mu \mathrm{m}$, for the composite formulations with $1 \mathrm{wt} .-\%$ CFs, down to below $600 \mu \mathrm{m}$, for those containing $10 \mathrm{wt} .-\%$ CFs. This corresponds to a decrease of the fiber aspect ratio from approximately 9 to 2.5 . Fiber lengths also decreased with increasing the screw speed, which is expected as stresses are larger for faster screw speeds. Interestingly, the green composite with $10 \mathrm{wt} .-\% \mathrm{CFs}$ presented the highest fiber length at $150 \mathrm{rpm}$, i.e. approximately $1179 \mu \mathrm{m}$, and also the lowest at $75 \mathrm{rpm}$, i.e. approximately $542 \mu \mathrm{m}$.

In order to correlate fiber attrition to melt viscosity, MFI was evaluated on the PHBV samples processed at $150 \mathrm{rpm}$. As one can observe in Fig. 5, the MFI values decreased with increasing the CFs content. This means that melt viscosity of the composite formulations was higher than the neat PHBV formulation and, thus, the intensity of the thermomechanical stresses raised. This was mainly related to the intensification of fiber-to-fiber collisions. While fiber dispersion requires stresses to be larger than the cohesive strength of the aggregates, larger stresses can also favor fibers rupture (Torres-Giner, 2016). As a result, composites formulated with more CFs presented higher viscosity and lower lengths. However, the lowest MFI value was observed for the composite formulation with $3 \mathrm{wt} . \mathrm{-} \% \mathrm{CFs}$ and then it increased for the larger CF contents. This viscosity decrease at high CF contents suggests an increase of biopolymer degradation or melt-shear thinning due to the presence of more fibers, which is known to occur in PHBV materials (Hilliou et al., 2016). Therefore, the complex interplay concerning reduced melt viscosity at higher $\mathrm{CF}$ contents, high residence times at low screw speeds, and thermal degradation of PHBV due to possible viscous heating, may explain the non-trivial evolution of fiber length.

From the above and within the experimental window tested herein, it was observed that the optimal screw speed to process the PHBV/CFs composites is $150 \mathrm{rpm}$. This processing condition delivered the most balanced fiber distribution, average fiber length, and intermediate residence times. In particular, the fiber aspect ratio remained in the 5.5-9.0 range, decreasing with increasing the CF content, and the residence time was of the order of $100 \mathrm{~s}$. It can be thus considered that this processing condition could be beneficial to process both thermally sensitive PHBV and thermolabile additives.

\subsection{Sheets characterization}

The green composite formulations melt-compounded at $150 \mathrm{rpm}$ were thereafter compression-molded into sheets and these were characterized in terms of their thermal, mechanical, and barrier properties.

Table 2 summarizes the thermal properties determined by DSC and TGA. Within the experimental precision, all PHBV sheets presented similar values of $\mathrm{T}_{\mathrm{g}}, \mathrm{T}_{\mathrm{c}}$, and $\mathrm{T}_{\mathrm{m}}$ (about $-3^{\circ} \mathrm{C}, 121^{\circ} \mathrm{C}$, and $173^{\circ} \mathrm{C}$, respectively). Similar results have been reported in the literature for other PHBV materials, indicating that the HV content plays the major role in defining the thermal transitions (Shang et al., 2012). In addition, cold crystallization was not observed and all the samples crystallized from the melt in a single peak. Interestingly, the presence of the CFs significantly affected the biopolymer degree of crystallization. While the neat PHBV sheet presented a $X_{c}$ of approximately $54 \%$, the addition of $1-5 \mathrm{wt} .-\%$ CFs reduced it to values in the $45-50 \%$ range and $X_{c}$ increased to about $58 \%$ for the $10 \mathrm{wt} .-\%$ CF content. This result suggests that crystal growth in the green composites was controlled by two competing factors, namely nucleation and confinement. As with other PHBV composites (Cunha et al., 2015), the presence of low contents of long fibers inhibited the chain-folding process of PHBV molecules, hindering molecular organization at the crystal growth front. Conversely, the existence of a high content of shorter fibers seems to provide a nucleating effect. The latter can be related to the degradation process triggered by the high CF content, as explained above, by which PHBV molecules were shorter and, thus, easier to crystallize.

Concerning the TGA data, also listed in Table 2, one can observe that thermal decomposition of the PHBV composites started in the range of $270-280^{\circ} \mathrm{C}$, presenting a degradation temperature $\left(\mathrm{T}_{\mathrm{deg}}\right)$ close to $300{ }^{\circ} \mathrm{C}$ with a mass loss of approximately $70 \%$. The incorporation of CFs slightly reduced the thermal stability of PHBV, but it also delayed the amount of mass loss during degradation. It is also worthy to note that the amount of residual mass increased, approximately from $3 \%$ to $6 \%$, which can be related to the presence of inorganic impurities in the fibers. In general, the addition of CFs up to $10 \mathrm{wt} .-\%$ did not significantly alter the thermal degradation profile of PHBV, thus, positively not impairing its processing window.

Table 3 shows the tensile properties of PHBV and its green composite with CFs. The neat PHBV sheet presented a tensile modulus of $c a$. 3.7 GPa, a tensile strength of $c a .34 \mathrm{MPa}$, and an elongation at break of ca.1.2\%. These properties clearly indicate that the PHBV sheets were rigid and brittle. As expected, the incorporation of CFs further increased, though not significantly, the tensile modulus and also reduced both the tensile strength and elongation at break. The same response has been reported for other compression-molded green composite sheets based on PHAs (Shibata, Oyamada, Kobayashi, \& Yaginuma, 2004; Torres-Giner, Montanes, Fombuena, et al., 2016), which have been mainly related to a poor fiber-matrix adhesion. The 5 wt.-\% CFcontaining sheet presented the highest tensile modulus, i.e. approximately $4.1 \mathrm{GPa}$, with tensile strength and elongation-at-break values of 
$75 \mathrm{rpm}$
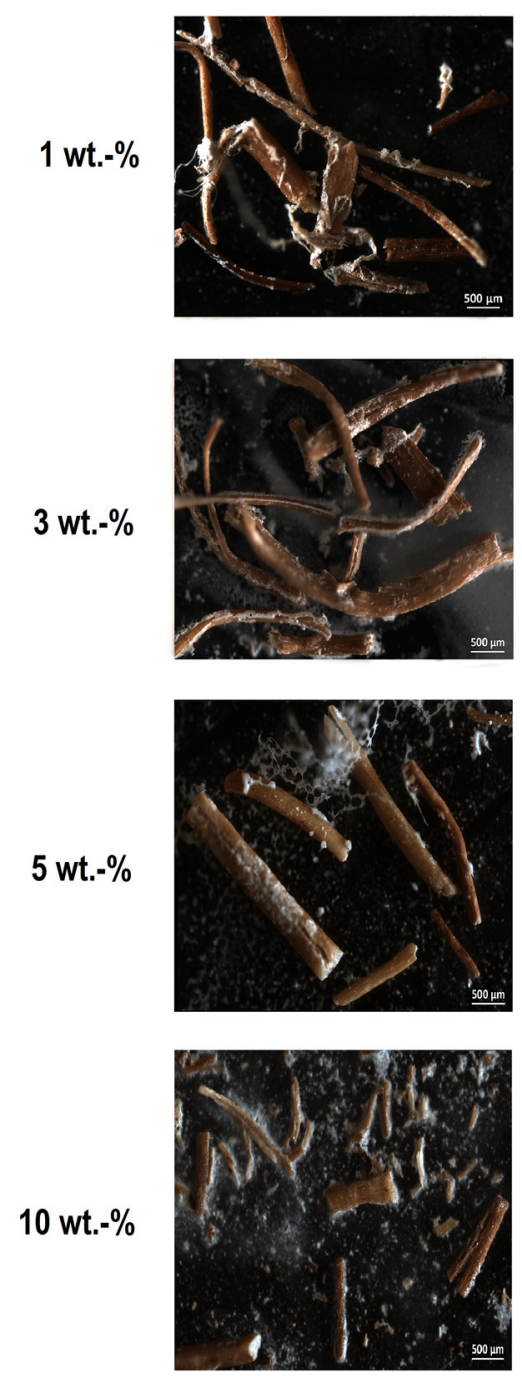

$150 \mathrm{rpm}$
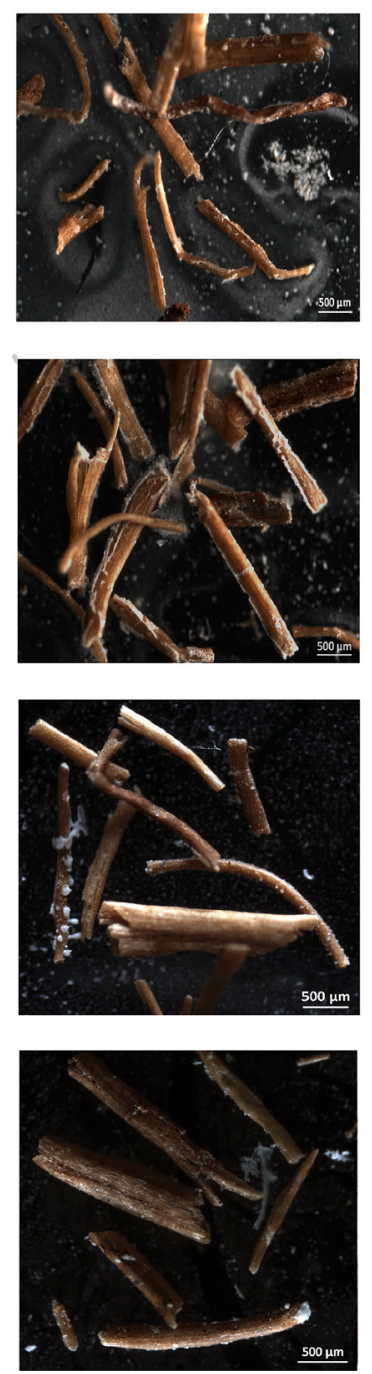

$225 \mathrm{rpm}$
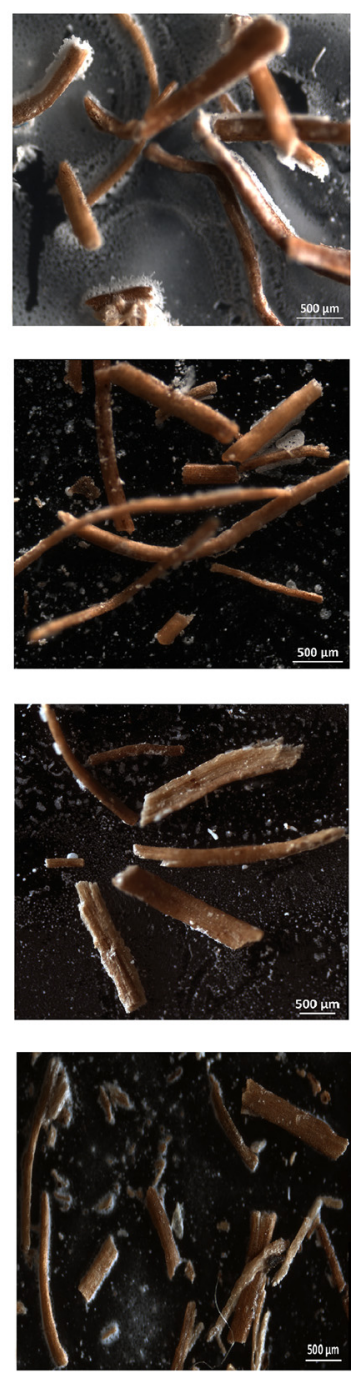

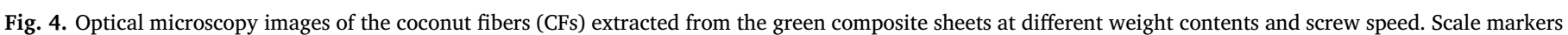
of $500 \mu \mathrm{m}$.

Table 1

Residence time $\left(t_{R}\right)$ and mean fiber length during melt compounding as a function of the poly(3-hydroxybutyrate-co-3-hydroxyvalerate) (PHBV) and coconut fibers (CFs) content and screw speed.

\begin{tabular}{lllll}
\hline $\begin{array}{l}\text { PHBV content } \\
(\text { wt.-\%) }\end{array}$ & $\begin{array}{l}\text { CF content } \\
(\text { wt.-\%) }\end{array}$ & $\begin{array}{l}\text { Screw speed } \\
(\mathrm{rpm})\end{array}$ & $\mathrm{t}_{\mathrm{R}}(\mathrm{s})$ & Fiber length $(\mu \mathrm{m})$ \\
\hline 100 & 0 & 75 & $131 \pm 3$ & \\
100 & 0 & 150 & $97 \pm 2$ & - \\
100 & 0 & 225 & $64 \pm 1$ & - \\
99 & 1 & 75 & $132 \pm 5$ & $1914.5 \pm 686.3$ \\
99 & 1 & 150 & $98 \pm 3$ & $1848.4 \pm 634.6$ \\
99 & 1 & 225 & $65 \pm 1$ & $1486.2 \pm 451.3$ \\
97 & 3 & 75 & $134 \pm 4$ & $1784.3 \pm 718.9$ \\
97 & 3 & 150 & $100 \pm 1$ & $1711.6 \pm 505.4$ \\
97 & 3 & 225 & $66 \pm 2$ & $1404.5 \pm 683.4$ \\
95 & 5 & 75 & $136 \pm 5$ & $1760.4 \pm 446.5$ \\
95 & 5 & 150 & $102 \pm 2$ & $1633.4 \pm 491.6$ \\
95 & 5 & 225 & $68 \pm 1$ & $1309.6 \pm 671.7$ \\
90 & 10 & 75 & $143 \pm 5$ & $542.3 \pm 190.8$ \\
90 & 10 & 150 & $106 \pm 3$ & $1178.9 \pm 333.9$ \\
90 & 10 & 225 & $70 \pm 2$ & $715.2 \pm 302.2$ \\
\hline
\end{tabular}

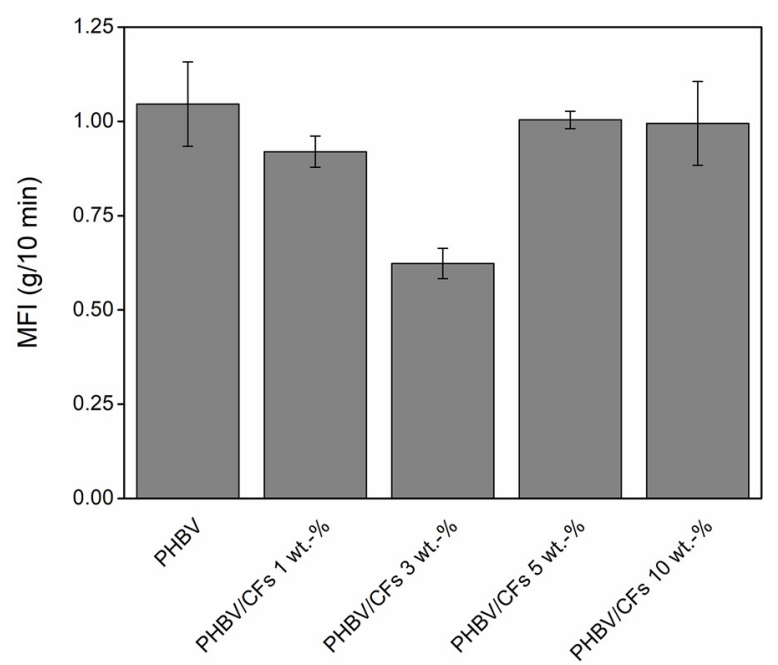

Fig. 5. Melt flow index (MFI) of the green composite pellets as function of the weight content of coconut fibers (CFs). Test performed at $185^{\circ} \mathrm{C}$ with a load of $1.2 \mathrm{~kg}$. 
Table 2

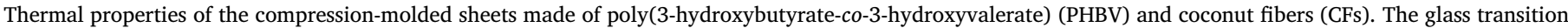

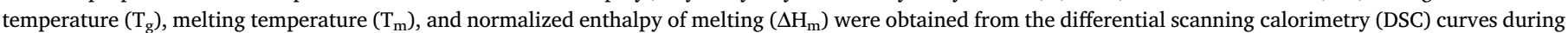

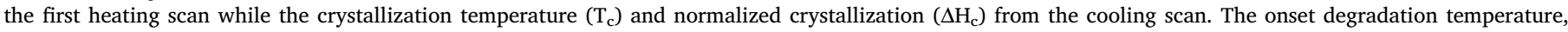

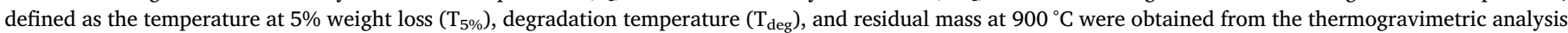
(TGA) curves.

\begin{tabular}{|c|c|c|c|c|c|c|c|c|c|c|}
\hline \multirow[t]{2}{*}{ Samples } & \multicolumn{6}{|c|}{ DSC parameters } & \multicolumn{4}{|c|}{ TGA parameters } \\
\hline & $\mathrm{T}_{\mathrm{g}}\left({ }^{\circ} \mathrm{C}\right)$ & $\mathrm{T}_{\mathrm{c}}\left({ }^{\circ} \mathrm{C}\right)$ & $\mathrm{T}_{\mathrm{m}}\left({ }^{\circ} \mathrm{C}\right)$ & $\Delta \mathrm{H}_{\mathrm{c}}(\mathrm{J} / \mathrm{g})$ & $\Delta \mathrm{H}_{\mathrm{m}}(\mathrm{J} / \mathrm{g})$ & $\mathrm{X}_{\mathrm{c}}(\%)$ & $\mathrm{T}_{5 \%}\left({ }^{\circ} \mathrm{C}\right)$ & $\mathrm{T}_{\mathrm{deg}}\left({ }^{\circ} \mathrm{C}\right)$ & Mass loss (\%) & Residual mass (\%) \\
\hline PHBV & $-3.3 \pm 0.8$ & $120.6 \pm 0.1$ & $172.8 \pm 0.2$ & $84.7 \pm 2.4$ & $79.4 \pm 0.9$ & $54.1 \pm 0.6$ & $277 \pm 0.3$ & $298 \pm 0.5$ & $72.19 \pm 0.6$ & $3.2 \pm 0.2$ \\
\hline PHBV/CFs 1 wt.- $\%$ & $-2.4 \pm 0.3$ & $120.2 \pm 0.9$ & $173.8 \pm 1.3$ & $78.3 \pm 4.2$ & $64.9 \pm 1.1$ & $44.7 \pm 0.8$ & $276 \pm 0.5$ & $296 \pm 0.5$ & $70.99 \pm 0.3$ & $3.5 \pm 0.2$ \\
\hline PHBV/CFs 3 wt.- $\%$ & $-2.3 \pm 0.9$ & $120.4 \pm 1.1$ & $173.9 \pm 1.4$ & $74.3 \pm 4.4$ & $66.6 \pm 3.5$ & $46.9 \pm 0.5$ & $275 \pm 0.4$ & $295 \pm 0.4$ & $70.78 \pm 0.4$ & $3.5 \pm 0.3$ \\
\hline PHBV/CFs 5 wt.-\% & $-2.2 \pm 0.4$ & $121.0 \pm 0.6$ & $172.9 \pm 0.5$ & $75.5 \pm 2.6$ & $69.8 \pm 2.7$ & $50.1 \pm 0.9$ & $274 \pm 0.5$ & $293 \pm 0.3$ & $64.85 \pm 0.5$ & $4.6 \pm 0.3$ \\
\hline PHBV/CFs 10 wt.- $\%$ & $-1.8 \pm 0.6$ & $119.8 \pm 0.5$ & $172.5 \pm 1.0$ & $76.8 \pm 3.0$ & $76.8 \pm 3.2$ & $58.2 \pm 1.4$ & $273 \pm 0.4$ & $291 \pm 0.4$ & $63.79 \pm 0.3$ & $5.8 \pm 0.2$ \\
\hline
\end{tabular}

\section{Table 3}

Mechanical properties of the compression-molded sheets made of poly(3-hydroxybutyrate-co-3-hydroxyvalerate) (PHBV) and coconut fibers (CFs) in terms of tensile modulus (E), tensile strength at yield $\left(\sigma_{\mathrm{y}}\right)$, and elongation at break $\left(\varepsilon_{\mathrm{b}}\right)$.

\begin{tabular}{llll}
\hline Sample & E $(\mathrm{MPa})$ & $\sigma_{\mathrm{y}}(\mathrm{MPa})$ & $\varepsilon_{\mathrm{b}}(\%)$ \\
\hline PHBV & $3671 \pm 180$ & $33.8 \pm 2.1$ & $1.18 \pm 0.15$ \\
PHBV/CFs 1 wt.-\% & $3815 \pm 164$ & $30.7 \pm 3.4$ & $1.06 \pm 0.10$ \\
PHBV/CFs 3 wt.-\% & $3916 \pm 288$ & $29.3 \pm 2.0$ & $0.95 \pm 0.04$ \\
PHBV/CFs 5 wt.-\% & $4093 \pm 197$ & $28.6 \pm 2.0$ & $0.88 \pm 0.12$ \\
PHBV/CFs 10 wt.-\% & $3720 \pm 125$ & $24.7 \pm 1.3$ & $0.67 \pm 0.09$ \\
\hline
\end{tabular}

approximately $29 \mathrm{MPa}$ and $0.9 \%$, respectively. It is also worthy to mention the low elastic modulus observed for the green composite sheet containing $10 \mathrm{wt} .-\% \mathrm{CFs}$, i.e. $\sim 3.7 \mathrm{GPa}$, which can be related to the presence of fibers with lower mean fiber lengths, as previously shown in Table 1 . The lowest values of tensile strength and elongation at break were also observed for the green composite sheet with $10 \mathrm{wt} .-\% \mathrm{CFs}$, i.e. approximately $25 \mathrm{MPa}$ and $0.7 \%$, respectively. Therefore, the CFs acted as an effective reinforcement of PHBV matrices when their length exceeds a critical threshold, in this case approximately $1500 \mu \mathrm{m}$, which corresponds to an aspect ratio close to 7. However, the exact mechanism for the reinforcement might go beyond the effect of fiber size, as both PHBV matrix thermal degradation and composite enhanced crystallinity in the sheet with $10 \mathrm{wt} .-\%$ CFs may add complexity to the mechanical-structural relationships.

Finally, the barrier properties to water vapor, limonene, and oxygen were determined and the permeability values are included in Table 4. The barrier performance is, in fact, one of the main parameters of application interest for food packaging. One can observe that the permeability to both water and limonene vapors slightly raised by increasing the CF content. Such increase was higher in the case of water vapor, reaching permeability values close to $4 \times 10^{-15} \mathrm{~kg} \mathrm{~m} \mathrm{~m}^{-2} \mathrm{~Pa}^{-1} \mathrm{~s}^{-1}$. Since water vapor is mainly a diffusivity-driven property in PHAs due to their low water sorption nature (Razumovskii, Iordanskii, Zaikov, Zagreba, \& McNeill, 1994), the increase in permeability to water vapor can be ascribed to the hydrophilic character of the filler and possibly also to increased free volume at the fiber-matrix interface. To put these values into a more packaging context, WVP values of the here-developed green composite sheets are in the same order of magnitude as their petroleum-based counterpart polyethylene terephthalate (PET) films, i.e. $2.30 \times 10^{-15} \mathrm{~kg} \mathrm{~m} \mathrm{~m}^{-2} \mathrm{~Pa}^{-1} \mathrm{~s}^{-1}$ (Lagaron, 2011).

Limonene transport properties are also important in packaging applications because this vapor is usually used as a standard system to test aroma barrier. The effect of fiber content on LP was relatively small and the neat PHBV and green composite sheets with CFs showed values in the range of $1.1-1.5 \times 10^{-14} \mathrm{~kg} \mathrm{~m} \mathrm{~m}^{-2} \mathrm{~Pa}^{-1} \mathrm{~s}^{-1}$. In this sense, limonene, as opposed to moisture, is a strong plasticizing component for PHAs and, then, solubility plays a more important role in permeability than diffusion. For example, Sanchez-Garcia, Gimenez, and Lagaron (2008) reported a limonene uptake of $c a .12 .7 \mathrm{wt} .-\%$ for films made of PHBV with 12 mol.-\% HV prepared by solvent casting, resulting in a LP value of $1.99 \times 10^{-13} \mathrm{~kg} \mathrm{~m} \mathrm{~m}^{-2} \mathrm{~Pa}^{-1} \mathrm{~s}^{-1}$. Interestingly, the here-prepared green composite sheets were 13-17 times more barrier to limonene, which can be ascribed to both the lower HV content of the hereused copolyester and also to the compression molding methodology. The observed increase in permeability when introducing CFs, though slight, may be related to a sorption phenomenon at the filler-matrix interface. In any case, the here-obtained PHBV-based sheets still presented LP values close to those previously reported for PHB films, i.e. $8.8 \times 10^{-15} \mathrm{~kg} \mathrm{~m} \mathrm{~m}^{-2} \mathrm{~Pa}^{-1} \mathrm{~s}^{-1}$, and approximately 8-10 times lower than PET films, i.e. $1.17 \times 10^{-13} \mathrm{~kg} \cdot \mathrm{m} \cdot \mathrm{m}^{-2} \cdot \mathrm{Pa}^{-1} \cdot \mathrm{s}^{-1}$, both obtained by compression molding (Sanchez-Garcia, Gimenez, \& Lagaron, 2007).

In relation to oxygen, the presence of CFs induced a slight reduction in permeability though the trend was not monotonic. Since oxygen is a noncondensable small permeant, the presence of the cellulosic fibers can block oxygen diffusion while the heterogeneities within the composite can serve as preferential paths for the oxygen molecules. The highest barrier effect was observed for the PHBV/CFs 5 wt.-\%, with a OP value of $1.73 \times 10^{-19} \mathrm{~m}^{3} \mathrm{~m} \mathrm{~m}^{-2} \mathrm{~Pa}^{-1} \mathrm{~s}^{-1}$, which is close to that of PET films, i.e. $1.35 \times 10^{-19} \mathrm{~m}^{3} \mathrm{~m} \mathrm{~m}^{-2} \mathrm{~Pa}^{-1} \mathrm{~s}^{-1}$ (Lagaron, 2011). This suggests that, at this intermediate fiber content, the contribution of the blocking effect over the heterogeneities was optimal. Overall, the hereobtained PHBV-based composite sheets presented OP values in the $0.7-0.8 \times 10^{-18} \mathrm{~m}^{3} \mathrm{~m} \mathrm{~m}^{-2} \mathrm{~Pa}^{-1} \mathrm{~s}^{-1}$ range, being slightly lower than those recently observed for electrospun homopolyester PHB films (Cherpinski, Torres-Giner, Cabedo, Méndez, \& Lagaron, 2017) but

Table 4

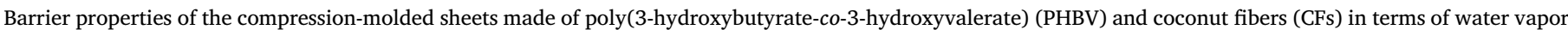
permeability (WVP), limonene permeability (LP), and oxygen permeability (OP).

\begin{tabular}{|c|c|c|c|}
\hline Sample & WVP $\times 10^{15}\left(\mathrm{~kg} \mathrm{~m} \mathrm{~m}^{-2} \mathrm{~Pa}^{-1} \mathrm{~s}^{-1}\right)$ & $\mathrm{LP} \times 10^{14}\left(\mathrm{~kg} \mathrm{~m} \mathrm{~m}^{-2} \mathrm{~Pa}^{-1} \mathrm{~s}^{-1}\right)$ & OP $\times 10^{18}\left(\mathrm{~m}^{3} \mathrm{~m} \mathrm{~m}^{-2} \mathrm{~Pa}^{-1} \mathrm{~s}^{-1}\right)$ \\
\hline PHBV & $1.83 \pm 0.47$ & $1.17 \pm 0.19$ & $0.80 \pm 0.14$ \\
\hline PHBV/CFs 1 wt.-\% & $1.93 \pm 0.34$ & $1.19 \pm 0.31$ & $0.77 \pm 0.09$ \\
\hline PHBV/CFs 3 wt.-\% & $3.60 \pm 0.46$ & $1.25 \pm 0.22$ & $0.73 \pm 0.08$ \\
\hline PHBV/CFs 5 wt.- $\%$ & $3.93 \pm 0.58$ & $1.38 \pm 0.27$ & $0.17 \pm 0.06$ \\
\hline PHBV/CFs 10 wt.- $\%$ & $3.96 \pm 0.57$ & $1.48 \pm 0.24$ & $0.74 \pm 0.05$ \\
\hline
\end{tabular}




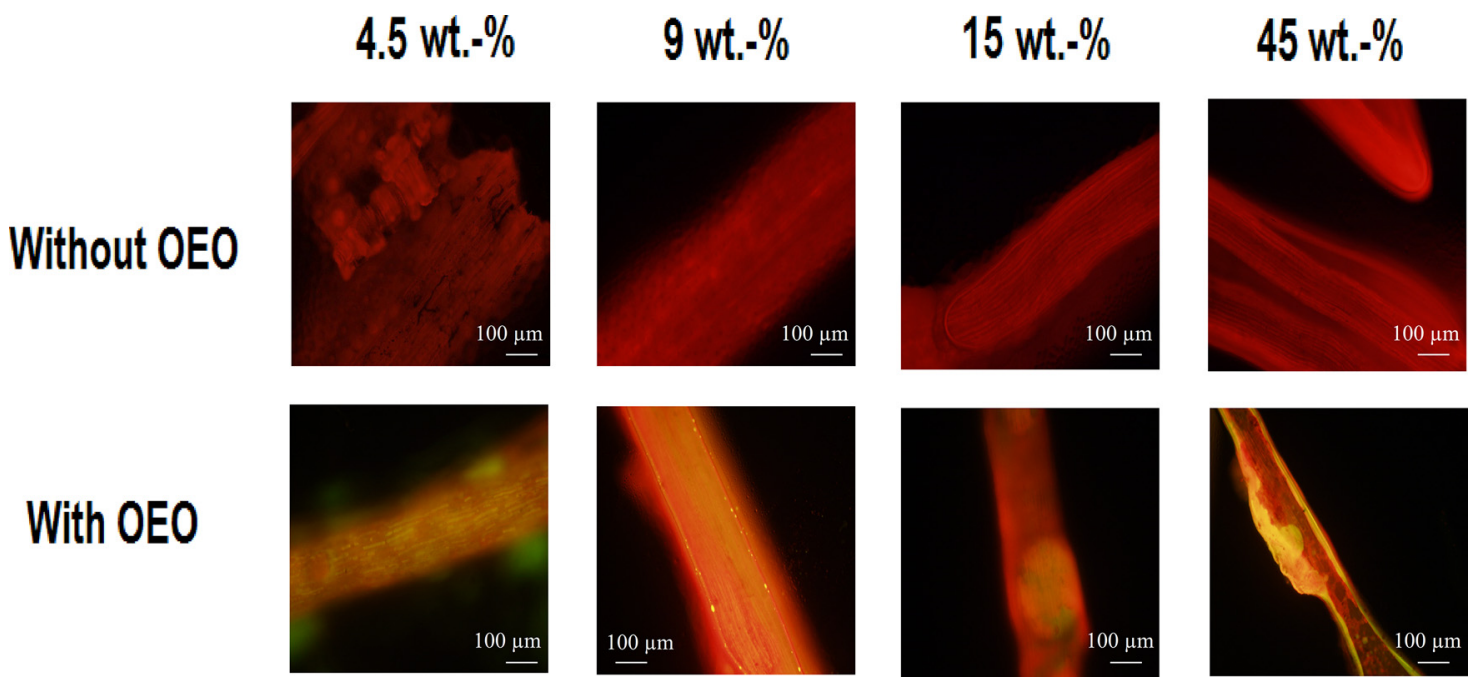

Fig. 6. Fluorescence microscopy images of the coconut fibers (CFs) impregnated with different weight contents of oil-oregano essential oil (OEO) mixture. Images were taken with an emission wavelength between 470 and $490 \mathrm{~nm}$. Scale markers of $100 \mu \mathrm{m}$.

higher than conventional 100- $\mu$ m PHB films prepared by compression molding (Sanchez-Garcia et al., 2007).

\subsection{Antibacterial activity}

In the last part of this study, the CFs were impregnated with different contents of an oil-OEO mixture by means of an in-house developed spraying methodology. Fig. 6 shows the fluorescence images taken by optical microscopy on the resultant OEO-containing fibers. One can observe that the oil-OEO mixture, shown as yellow-to-orange areas in the images, was homogenously distributed along the fibers surface for contents up to 15 wt.-\%. However, at the highest tested content, i.e. $45 \mathrm{wt} .-\%$, the oily extract eventually saturated the fibers and accumulated around their outer surface. Based on this observation, the CFs containing $15 \mathrm{wt} .-\%$ oil-OEO mixture, which in turns provided a final content of $5 \mathrm{wt} .-\%$ OEO, were selected to further functionalize the green composites with antibacterial properties. As the CF content in the biopolymer was kept at $1-10 \mathrm{wt} .-\%$, this resulted in a concentration range of $0.05-0.5$ wt.- $\%$ OEO in the PHBV sheets.

The MIC values, defined as the lowest concentration of a biocide substance that is capable of inhibiting bacterial growth, of both the neat OEO and OEO-containing CFs were determined using the plate microdilution protocol. While the neat OEO presented a MIC value against $S$. aureus of $0.312 \mu \mathrm{l} / \mathrm{ml}$, this value was significantly higher for the OEO- containing CFs, i.e. $25 \mu \mathrm{g} / \mathrm{ml}$, which corresponds to a OEO concentration of $1.25 \mu \mathrm{g} / \mathrm{ml}$. This reduction in antibacterial effectiveness, of about 4 times, can be related to partial losses during the spraying process, a heterogeneous distribution of the OEO, and/or to an in-depth entrapment of the antibacterial oil into fibers regions that were not accessible for interaction with bacteria (e.g. pores). It is also worthy to indicate that the here-reported MIC values for OEO were relatively low, being for instance one order of magnitude lower than those reported by dos Santos Rodrigues et al. (2017) against different planktonic and sessile cells of $S$. aureus isolates.

In relation to the possible biological mechanism exerted by OEO on S. aureus, Dadalioğlu and Evrendilek (2004) attributed this effect to two particular components: the phenolic compound carvacrol and the monoterpene p-cymene. According to Zivanovic et al. (2005), the proposed action of phenolic compounds is based on their attack on the phospholipid cell membrane, which causes increased permeability and leakage of cytoplasm, or on their interaction with enzymes located at the cell wall. Indeed, most studies investigating the antibacterial activity of OEO agree that, generally, the extract is slightly more active against Gram-positive $(\mathrm{G}+$ ) than Gram-negative $(\mathrm{G}-$ ) bacteria (Burt, 2004; Hosseini et al., 2015; Zivanovic et al., 2005). Not only the type of bacteria but also the source and concentration of the active plant extract compounds and the film composition play a key role in the antimicrobial activity of OEO. For instance, whey protein isolated (WPI)-

Table 5

Antibacterial activity against Staphylococcus aureus of the compression-molded sheets made of poly(3-hydroxybutyrate-co-3-hydroxyvalerate) (PHBV) and coconut fibers (CFs) loaded with oregano essential oil (OEO).

\begin{tabular}{|c|c|c|c|c|}
\hline \multirow[t]{2}{*}{ Sample } & \multicolumn{2}{|l|}{ Initial } & \multicolumn{2}{|l|}{ After 15 days } \\
\hline & $\begin{array}{l}\text { Bacterial } \\
\text { counts } \\
{[\log (\mathrm{CFU} / \mathrm{ml})]}\end{array}$ & $\mathrm{R}$ & $\begin{array}{l}\text { Bacterial } \\
\text { counts } \\
{[\log (\mathrm{CFU} / \mathrm{ml})]}\end{array}$ & $\mathrm{R}$ \\
\hline Inoculation & $5.69 \pm 0.10$ & - & $5.69 \pm 0.10$ & - \\
\hline Control $(\mathrm{t}=0 \mathrm{~h})$ & $5.70 \pm 0.03$ & - & $5.68 \pm 0.44$ & - \\
\hline Control $(t=24 h)$ & $5.69 \pm 0.03$ & - & $5.68 \pm 0.44$ & - \\
\hline PHBV & $5.32 \pm 0.50$ & $0.37 \pm 0.49$ & $5.30 \pm 0.05$ & $0.38 \pm 0.41$ \\
\hline PHBV/CFs 1 wt.- $\%$ & $5.48 \pm 0.18$ & $0.21 \pm 0.15$ & $5.42 \pm 0.51$ & $0.26 \pm 0.65$ \\
\hline PHBV/CFs 1 wt.- $\%$ + OEO & $4.72 \pm 0.05$ & $0.97 \pm 0.18$ & $5.56 \pm 0.17$ & $0.12 \pm 0.29$ \\
\hline PHBV/CFs 3 wt.- $\%$ & $5.39 \pm 1.11$ & $0.30 \pm 1.14$ & $5.54 \pm 0.56$ & $0.14 \pm 0.47$ \\
\hline PHBV/CFs 3 wt.- $\%$ + OEO & $4.21 \pm 0.50$ & $1.48 \pm 0.64$ & $4.78 \pm 0.09$ & $0.90 \pm 0.65$ \\
\hline PHBV/CFs 5 wt.-\% & $5.36 \pm 0.50$ & $0.33 \pm 0.51$ & $5.62 \pm 0.05$ & $0.06 \pm 0.45$ \\
\hline PHBV/CFs 5 wt.- $\%$ + OEO & $4.15 \pm 0.70$ & $1.54 \pm 0.53$ & $4.58 \pm 0.09$ & $1.10 \pm 0.12$ \\
\hline PHBV/CFs 10 wt.- $\%$ & $5.35 \pm 0.09$ & $0.34 \pm 0.09$ & $5.60 \pm 0.16$ & $0.08 \pm 0.56$ \\
\hline PHBV/CFs 10 wt.- $\%$ + OEO & $3.96 \pm 0.33$ & $1.73 \pm 0.40$ & $4.32 \pm 0.26$ & $1.36 \pm 0.41$ \\
\hline
\end{tabular}


based films with 1 wt./vol.-\% OEO prepared by Oussalah et al. (2004) were effective against different bacterial colonies on the surface of beef. However, Seydim and Sarikus (2006) observed that a content of at least 2 wt.-\% OEO in WPI films was needed to reach the minimum inhibitory level against the same bacteria.

Finally, Table 5 includes the antibacterial effect against $S$. aureus of the green composite sheets with varying functionalized CF contents. It can be observed that both the unfilled PHBV sheet and the different green composite sheets containing CFs without OEO showed no inhibition effect on the bacterial growth $(R \leq 0.5)$. In contrast, the incorporation of OEO-containing CFs into the PHVB sheets exhibited a significant antibacterial activity. At the initial day, i.e. for the tests carried out 1 day after production of the green composite sheets, bacterial reduction on the sheets surface gradually increased with the OEOcontaining CFs content. At the lowest content, i.e. $1 \mathrm{wt} .-\%$ OEO-containing CFs, the green composite sheet presented a slight antibacterial activity $(\mathrm{R}=0.97)$. For higher contents, i.e. 3-10 wt.-\% OEO-containing CFs, the sheets generated a significant surface reduction $(R \geq 1$ and $<3$ ). Although none of the sheets produced a strong reduction $(\mathrm{R} \geq 3$ ), contents as low as 3 wt.-\% OEO-containing CFs successfully inhibited the bacterial growth. Indeed, materials with surface reduction values in the range 1-2 are usually considered as bacteriostatic (Fabra, Pourrahimi, Olsson, \& Lagaron, 2017). Therefore, final OEO contents of only 0.15 wt. $\%$ in the green composites, which corresponds to a OEOcontaining CFs loading of $3 \mathrm{wt} . \%$, were able to provide a bacteriostatic effect against $S$. aureus. As also shown in the table, after 15 days, the green composite sheets successfully kept a significant antibacterial activity. In particular, the sheets with OEO-containing CFs loadings of 5 and 10 wt.- $\%$ still presented significant $(R \geq 1$ and $<3$ ) values of reduction while these presented slight $(R \geq 0.5$ and $<1)$ and nonsignificant $(R \leq 0.5)$ values for loadings of 3 and $1 \mathrm{wt} .-\%$, respectively. This suggests that, though part of OEO was released from the sheets over time, the CFs were still able to retain a significant amount of the active oil.

Previous studies based on films loaded with OEO against food spoilage microorganisms have shown that a minimum concentration of approximately $1 \mathrm{wt}$. $\%$ of active material was necessary to ensure antibacterial efficacy. For instance, Benavides et al. (2012) incorporated OEO in alginate films prepared by solvent casting where active contents at a level of $1.0 \mathrm{wt}$./vol.- $\%$ provided antibacterial properties. In another study, Hosseini et al. (2015) prepared OEO-containing fish gelatin/ chitosan films also by the casting method, showing antimicrobial performance at $1.2 \mathrm{wt}$./vol.-\%. Pelissari et al. (2009) recently produced starch/chitosan films in which OEO was incorporated at $0.1-1 \mathrm{wt} .-\%$ by blow film extrusion. The antimicrobial activity against $S$. aureus was only evaluated qualitatively by the disk inhibition zone assay, producing halos between 13.26 and $30.81 \mathrm{~mm}$. The here-attained results then suggest that antimicrobial efficiency of the green composites based on OEO-containing CFs is about 6-7 times higher than that observed in previous research works. However, all these studies are certainly difficult to compare in a straight way, even for the same bacteria, due to differences in the film nature, the selected methodology of film preparation, the performed antimicrobial test, etc.

\section{Conclusions}

The first part of the present study was focused on finding the right processing conditions to optimally prepare green composites made of PHBV and CFs. Incorporation of different weight contents of CFs into a PHBV matrix was successfully achieved by TSE, varying the screw speed, and afterward shaped into sheets by compression molding. Optimal incorporation of the CFs into the PHBV matrix was attained at $150 \mathrm{rpm}$ since this provided the best balance between dispersion and fiber attrition. This processing condition led to easily processable green composite formulations with the most balanced fiber distribution, average fiber length, and intermediate residence times. In particular, the fibers aspect ratio varied from 5.5 to 9 , which decreased with increasing the CF content, and the residence time was of the order of $100 \mathrm{~s}$. It was considered that this processing condition is beneficial to process both PHBV, due to its intrinsic narrow processing window and poor melt strength, and OEO, which is thermolabile and easily evaporates and/or decomposes during processing. In the second part of the study, the green composite sheets prepared at $150 \mathrm{rpm}$ were fully characterized in terms of their thermal, mechanical, and barrier properties. Results showed that the incorporation of CFs into PHBV generated green composite sheets with similar thermal stability, even at the highest content, thus positively not impairing its processing window. In general, the green composites presented a slightly higher rigidity but lower ductility. It was particularly observed that the CFs acted as an effective reinforcement in the PHBV matrix when their length exceeds a critical threshold of $1500 \mu \mathrm{m}$, which corresponds to an aspect ratio close to 7 . In relation to the barrier properties, it was observed that both the WVP and LP values were slightly reduced due to the CFs presence, which was related to a sorption phenomenon at the filler-matrix interface. Interestingly, the oxygen barrier performance was improved for intermediate CFs contents due to the contribution of the blocking effect over the heterogeneities was optimal. Finally, in the third part of the study, the CFs were impregnated with different OEO contents by an inhouse developed spraying methodology and thereafter incorporated again into the green composites to generate sheets with antibacterial activity. Through this approach, it was possible to successfully achieve bacteriostatic effect against $S$. aureus from OEO-containing CF contents of only $3 \mathrm{wt} .-\%$. This was ascribed to the high capacity of CFs to entrap active substances, being able to resist typical processing conditions of thermoplastic materials produced in the packaging industry. Interestingly, OEO was released in a slow manner to the green composite sheet surface, remaining at effective concentrations for a period of at least 15 days.

The scientific merit of this work relays on the development of a fully bio-based formulation, where a natural antimicrobial is incorporated within the structure of an agro-food waste filler, which then acts as a carrier. In addition, the filler also serves to improve the physical performance and potentially reduce the cost of the overall formulation giving the current high price of commercial PHBV. This technology adds to actual strategies to pursue Circular Economy's approaches for the design of packaging materials. The active antimicrobial performance is, indeed, an added value also for the formulation because it will potentially increase the food quality and safety of the packed foods.

\section{Acknowledgements}

This research was funded by the EU H2020 project YPACK (reference number 773872), the Spanish Ministry of Economy and Competitiveness (MINECO) project AGL2015-63855-C2-1-R, the Portuguese Foundation for Science and Technology (FCT) under the scope of the strategic funding of UID/BIO/04469/2013 unit and COMPETE 2020 (POCI-01-0145-FEDER-006684), and the BioTecNorte operation (NORTE-01-0145-FEDER-000004) funded by the European Regional Development Fund (ERDF) under the scope of Norte2020 Programa Operacional Regional do Norte. Prof. Sergio Torres-Giner wants to thank the European Cooperation in Science and Technology (COST) Action FP1405, ActInPak, for financial support during his Short Term Scientific Mission (STSM) at the University of Minho.

\section{References}

Avella, M., Rota, G. L., Martuscelli, E., Raimo, M., Sadocco, P., Elegir, G., \& Riva, R. (2000). Poly(3-hydroxybutyrate-co-3-hydroxyvalerate) and wheat straw fibre composites: Thermal, mechanical properties and biodegradation behaviour. Journal of Materials Science, 35(4), 829-836.

Barham, P. J., Keller, A., Otun, E. L., \& Holmes, P. A. (1984). Crystallization and morphology of a bacterial thermoplastic: Poly-3-hydroxybutyrate. Journal of Materials Science, 19(9), 2781-2794. 
Barkoula, N. M., Garkhail, S. K., \& Peijs, T. (2010). Biodegradable composites based on flax/polyhydroxybutyrate and its copolymer with hydroxyvalerate. Industrial Crops and Products, 31(1), 34-42.

Benavides, S., Villalobos-Carvajal, R., \& Reyes, J. E. (2012). Physical, mechanical and antibacterial properties of alginate film: Effect of the crosslinking degree and oregano essential oil concentration. Journal of Food Engineering, 110(2), 232-239.

Bhatnagar, A., Vilar, V. J. P., Botelho, C. M. S., \& Boaventura, R. A. R. (2010). Coconutbased biosorbents for water treatment - A review of the recent literature. Advances in Colloid and Interface Science, 160(1), 1-15.

Bogoeva-Gaceva, G., Avella, M., Malinconico, M., Buzarovska, A., Grozdanov, A., Gentile, G., et al. (2007). Natural fiber eco-composites. Polymer Composites, 28(1), 98-107.

Bugnicourt, E., Cinelli, P., Lazzeri, A., \& Alvarez, V. (2014). Polyhydroxyalkanoate (PHA): Review of synthesis, characteristics, processing and potential applications in packaging. Express Polymer Letters, 8(11), 791-808.

Burt, S. (2004). Essential oils: Their antibacterial properties and potential applications in foods-A review. International Journal of Food Microbiology, 94(3), 223-253.

Castro-Mayorga, J. L., Fabra, M. J., Pourrahimi, A. M., Olsson, R. T., \& Lagaron, J. M. (2017). The impact of zinc oxide particle morphology as an antimicrobial and when incorporated in poly(3-hydroxybutyrate-co-3-hydroxyvalerate) films for food packaging and food contact surfaces applications. Food and Bioproducts Processing, 101(Supplement C), 32-44.

Cherpinski, A., Torres-Giner, S., Cabedo, L., Méndez, J. A., \& Lagaron, J. M. (2017). Multilayer structures based on annealed electrospun biopolymer coatings of interest in water and aroma barrier fiber-based food packaging applications. Journal of Applied Polymer Science, 135(24), 45501.

Choudhury, A., Kumar, S., \& Adhikari, B. (2007). Recycled milk pouch and virgin lowdensity polyethylene/linear low-density polyethylene based coir fiber composites. Journal of Applied Polymer Science, 106(2), 775-785.

Corradini, E., de Morais, L. C., Rosa, M. F., Mazzetto, S. E., Mattoso, L. H. C., \& Agnelli, J. A. M. (2006). A preliminary study for the use of natural fibers as reinforcement in starch-gluten-glycerol matrix. Macromolecular Symposia, 245-246(1), 558-564.

Cunha, M., Berthet, M.-A., Pereira, R., Covas, J. A., Vicente, A. A., \& Hilliou, L. (2015). Development of polyhydroxyalkanoate/beer spent grain fibers composites for film blowing applications. Polymer Composites, 36(10), 1859-1865.

Dadalioğlu, I., \& Evrendilek, G. A. (2004). Chemical compositions and antibacterial ef fects of essential oils of Turkish oregano (Origanum minutiflorum), Bay laurel (Laurus nobilis), Spanish Lavender (Lavandula stoechas L.), And fennel (Foeniculum vulgare) on Common foodborne pathogens. Journal of Agricultural and Food Chemistry, 52(26), 8255-8260.

dos Santos Rodrigues, J. B., de Carvalho, R. J., de Souza, N. T., de Sousa Oliveira, K., Franco, O. L., Schaffner, D., de Souza, E. L., et al. (2017). Effects of oregano essential oil and carvacrol on biofilms of Staphylococcus aureus from food-contact surfaces. Food Control, 73(Part B), 1237-1246.

Faruk, O., Bledzki, A. K., Fink, H.-P., \& Sain, M. (2014). Progress report on natural fiber reinforced composites. Macromolecular Materials and Engineering, 299(1), 9-26.

Geethamma, V. G., Thomas Mathew, K., Lakshminarayanan, R., \& Thomas, S. (1998). Composite of short coir fibres and natural rubber: Effect of chemical modification, loading and orientation of fibre. Polymer, 39(6), 1483-1491.

Gu, H. (2009). Tensile behaviours of the coir fibre and related composites after $\mathrm{NaOH}$ treatment. Materials \& Design, 30(9), 3931-3934.

Hasan, M., Hoque, M. E., Mir, S. S., Saba, N., \& Sapuan, S. M. (2015). Manufacturing of coir fibre-reinforced polymer composites by Hot compression technique. In M. S. Salit, M. Jawaid, N. B. Yusoff, \& M. E. Hoque (Eds.). Manufacturing of natural fibre reinforced polymer composites (pp. 309-330). Cham: Springer International Publishing.

Hilliou, L., Teixeira, P. F., Machado, D., Covas, J. A., Oliveira, C. S. S., Duque, A. F., et al. (2016). Effects of fermentation residues on the melt processability and thermomechanical degradation of PHBV produced from cheese whey using mixed microbial cultures. Polymer Degradation and Stability, 128(Supplement C), 269-277.

Hosseini, S. F., Rezaei, M., Zandi, M., \& Farahmandghavi, F. (2015). Bio-based composite edible films containing Origanum vulgare L. essential oil. Industrial Crops and Products, 67, 403-413.

Hosseini, S. F., Zandi, M., Rezaei, M., \& Farahmandghavi, F. (2013). Two-step method for encapsulation of oregano essential oil in chitosan nanoparticles: Preparation, characterization and in vitro release study. Carbohydrate Polymers, 95(1), 50-56.

Joshi, S. V., Drzal, L. T., Mohanty, A. K., \& Arora, S. (2004). Are natural fiber composites environmentally superior to glass fiber reinforced composites? Composites Part A Applied Science and Manufacturing, 35(3), 371-376.

Kunioka, M., Tamaki, A., \& Doi, Y. (1989). Crystalline and thermal properties of bacterial copolyesters: Poly(3-hydroxybutyrate-co-3-hydroxyvalerate) and Poly(3-hydroxybutyrate-co-4-hydroxybutyrate). Macromolecules, 22(2), 694-697.

Lagaron, J. M. (2011). 1 - Multifunctional and nanoreinforced polymers for food packaging. Multifunctional and nanoreinforced polymers for food packaging. Cambridge, UK: Woodhead Publishing1-28.

López, P., Sánchez, C., Batlle, R., \& Nerín, C. (2007). Development of flexible antimicrobial films using essential oils as active agents. Journal of Agricultural and Food
Chemistry, 55(21), 8814-8824.

Mir, S. S., Nafsin, N., Hasan, M., Hasan, N., \& Hassan, A. (2013). Improvement of physicomechanical properties of coir-polypropylene biocomposites by fiber chemical treatment. Materials \& Design (1980-2015), 52(Supplement C), 251-257.

Oussalah, M., Caillet, S., Salmiéri, S., Saucier, L., \& Lacroix, M. (2004). Antimicrobial and antioxidant effects of milk protein-based film containing essential oils for the preservation of whole beef muscle. Journal of Agricultural and Food Chemistry, 52(18), $5598-5605$.

Owolabi, O., \& Czvikovszky, T. (1988). Composite materials of radiation-treated coconut fiber and thermoplastics. Journal of Applied Polymer Science, 35(3), 573-582.

Pelissari, F. M., Grossmann, M. V. E., Yamashita, F., \& Pineda, E. A. G. (2009). Antimicrobial, mechanical, and barrier properties of cassava starch - chitosan films incorporated with oregano essential oil. Journal of Agricultural and Food Chemistry, 57(16), 7499-7504.

Razumovskii, L. P., Iordanskii, A. L., Zaikov, G. E., Zagreba, E. D., \& McNeill, I. C. (1994) Sorption and diffusion of water and organic solvents in poly( $\beta$-hydroxybutyrate) films. Polymer Degradation and Stability, 44(2), 171-175.

Rosa, M. F., Chiou, B.-s., Medeiros, E. S., Wood, D. F., Williams, T. G., Mattoso, L. H. C., et al. (2009). Effect of fiber treatments on tensile and thermal properties of starch/ ethylene vinyl alcohol copolymers/coir biocomposites. Bioresource Technology, 100(21), 5196-5202.

Rosa, M. F., Medeiros, E. S., Malmonge, J. A., Gregorski, K. S., Wood, D. F., Mattoso, L. H. C., et al. (2010). Cellulose nanowhiskers from coconut husk fibers: Effect of preparation conditions on their thermal and morphological behavior. Carbohydrate Polymers, 81(1), 83-92.

Sanchez-Garcia, M. D., Gimenez, E., \& Lagaron, J. M. (2007). Novel PET nanocomposites of interest in food packaging applications and comparative barrier performance with biopolyester nanocomposites. Journal of Plastic Film \& Sheeting, 23(2), 133-148.

Sanchez-Garcia, M. D., Gimenez, E., \& Lagaron, J. M. (2008). Morphology and barrier properties of solvent cast composites of thermoplastic biopolymers and purified cellulose fibers. Carbohydrate Polymers, 71(2), 235-244.

Satyanarayana, K. G., Pillai, C. K. S., Sukumaran, K., Pillai, S. G. K., Rohatgi, P. K., \& Vijayan, K. (1982). Structure property studies of fibres from various parts of the coconut tree. Journal of Materials Science, 17(8), 2453-2462.

Seydim, A. C., \& Sarikus, G. (2006). Antimicrobial activity of whey protein based edible films incorporated with oregano, rosemary and garlic essential oils. Food Research International, 39(5), 639-644.

Shang, L., Fei, Q., Zhang, Y. H., Wang, X. Z., Fan, D.-D., \& Chang, H. N. (2012). Thermal properties and biodegradability studies of poly(3-hydroxybutyrate-co-3-hydroxyvalerate). Journal of Polymers and the Environment, 20(1), 23-28.

Shibata, M., Oyamada, S., Kobayashi, S., \& Yaginuma, D. (2004). Mechanical composites and biodegragability of green composites based on biodegradable polyesters and lyocell fabric. Journal of Applied Polymer Science, 92(6), 3857-3863.

Teramoto, N., Urata, K., Ozawa, K., \& Shibata, M. (2004). Biodegradation of aliphatic polyester composites reinforced by abaca fiber. Polymer Degradation and Stability, 86(3), 401-409.

Tomczak, F., Sydenstricker, T. H. D., \& Satyanarayana, K. G. (2007). Studies on lignocellulosic fibers of Brazil. Part II: Morphology and properties of Brazilian coconut fibers. Composites Part A: Applied Science and Manufacturing, 38(7), 1710-1721.

Torres-Giner, S. (2016). Preparation of conductive carbon black-filled polymer nanocomposites via melt compounding. Conductive Materials and Composites. New York, US: Nova Science Publishers, Inc117-164.

Torres-Giner, S., Montanes, N., Boronat, T., Quiles-Carrillo, L., \& Balart, R. (2016). Melt grafting of sepiolite nanoclay onto poly(3-hydroxybutyrate-co-4-hydroxybutyrate) by reactive extrusion with multi-functional epoxy-based styrene-acrylic oligomer. European Polymer Journal, 84(Supplement C), 693-707.

Torres-Giner, S., Montanes, N., Fombuena, V., Boronat, T., \& Sanchez-Nacher, L. (2016) Preparation and characterization of compression-molded green composite sheets made of poly(3-hydroxybutyrate) reinforced with long pita fibers. Advances in Polymer Technology. http://dx.doi.org/10.1002/adv.21789.

Torres-Giner, S., Torres, A., Ferrándiz, M., Fombuena, V., \& Balart, R. (2017) Antimicrobial activity of metal cation-exchanged zeolites and their evaluation on injection-molded pieces of bio-based high-density polyethylene. Journal of Food Safety, 37(4), e12348.

Wambua, P., Ivens, J., \& Verpoest, I. (2003). Natural fibres: Can they replace glass in fibre reinforced plastics? Composites Science and Technology, 63(9), 1259-1264.

Westerlind, B. S., \& Berg, J. C. (1988). Surface energy of untreated and surface-modified cellulose fibers. Journal of Applied Polymer Science, 36(3), 523-534.

Yang, H.-S., Kim, H.-J., Park, H.-J., Lee, B.-J., \& Hwang, T.-S. (2006). Water absorption behavior and mechanical properties of lignocellulosic filler-polyolefin bio-composites. Composite Structures, 72(4), 429-437.

Zini, E., \& Scandola, M. (2011). Green composites: An overview. Polymer Composites, 32(12), 1905-1915.

Zivanovic, S., Chi, S., \& Draughon, A. F. (2005). Antimicrobial activity of chitosan films enriched with essential oils. Journal of Food Science, 70(1), M45-M51. 